\title{
Tissue engineering using mesenchymal stem cells with periosteal wrap for bone defect repair in rabbits
}

\author{
Trung-Hau Lê Thua1, Dang-Nhat Pham¹, Khanh-Linh Lề ${ }^{1}$ Minh-Tuan Lế, \\ Quang-Ton-Quyen Nguyen', Phan-Huy Nguyen', Ngoc-Vu Tran², Ngoc-Luong Nguyen ${ }^{3}$, \\ Willy Boeckx ${ }^{4}$, Albert Demey ${ }^{4}$
}

${ }^{1}$ Department of Plastic, Reconstructive and Hand Surgery, Center of Orthopaedic and Plastic Surgery, Hue Central Hospital, Hue City 531120, Vietnam.

${ }^{2}$ Department of Hematology, Hue Central Hospital, Hue City 531120, Vietnam.

${ }^{3}$ Department of Biology, College of Sciences, Hue University, Hue City 521120, Vietnam.

${ }^{4}$ Department of Plastic Surgery, Brugmann University Hospital, Université libre de Bruxelles, 1020 Brussels, Belgium.

Address for correspondence: Dr. Trung-Hau Lê Thua, Department of Plastic, Reconstructive and Hand Surgery, Center of Orthopaedic and Plastic Surgery, Hue Central Hospital, Hue City 531120, Vietnam. E-mail: donabirini@yahoo.com

\begin{abstract}
Aim: Mesenchymal stem cells (MSCs) are an excellent potential source of cells for bone tissue engineering due to their excellent renewal ability and osteogenic differentiation capabilities. This study was designed to evaluate the bone formation properties of a demineralized cancellous bone scaffold seeded with MSCs, with or without periosteum, in a critical size bone defect model in rabbits. Methods: Rabbit culture-expanded bone marrow (BM)-MSCs were seeded onto a human demineralized cancellous bone (HDCB) scaffold. Bone defects measuring $15 \mathrm{~mm}$ in length were created in each radius. A total of 56 bone defects in 28 rabbits were randomly assigned to one of the 4 groups for scaffold implantation: Group 1: HDCB graft only; Group 2: periosteum-wrapped HDCB graft; Group 3: HDCB graft seeded with BM-MSCs and Group 4: periosteum-wrapped HDCB graft seeded with BM-MSCs. All rabbits were sacrificed 12 weeks after surgery for gross observation, radiological assessment, histological analyses and biomechanical measurements. Results: New bone (NB) formation and bone healing were successfully achieved, both radiologically and histologically, on demineralized cancellous bone graft seeded with BM-MSCs. Results were improved when BM-MSCs were associated with periosteum. Conclusion: This study demonstrates that repair of bone defects in a rabbit model can be achieved through bone grafting using BM-MSCs, implanted on a demineralized cancellous bone scaffold. The formation of NB was optimized when combined with the preservation of periosteum at the site of injury.
\end{abstract}

Key words:

Bone defects, bone marrow, bone tissue engineering, mesenchymal stem cells, periosteum

\section{INTRODUCTION}

Despite numerous advances in orthopedic and plastic surgery, the repair of bone defects remains challenging. The

\begin{tabular}{|l|l|}
\hline \multicolumn{2}{|c|}{ Access this article online } \\
\hline Quick Response Code: & Website: \\
\hline & www.parjournal.net \\
\cline { 2 - 2 } & \\
\hline
\end{tabular}

most desirable material for bone repair is autologous bone graft, due to its excellent osteoconduction, osteoinduction

This is an open access article distributed under the terms of the Creative Commons Attribution-NonCommercial-ShareAlike 3.0 License, which allows others to remix, tweak, and build upon the work non-commercially, as long as the author is credited and the new creations are licensed under the identical terms.

For reprints contact: reprints@medknow.com

How to cite this article: Lê Thua TH, Pham DN, Lê KL, Lê MT, Nguyen QT, Nguyen PH, Tran NV, Nguyen NL, Boeckx W, Demey A. Tissue engineering using mesenchymal stem cells with periosteal wrap for bone defect repair in rabbits. Plast Aesthet Res 2015;2:340-5.

Received: 04-04-2015; Accepted: 06-09-2015 
and osteogenesis properties. ${ }^{[1,2]}$ However, its limitations include additional surgical exposure required for graft harvest, limited bone supply and associated donor site morbidities. ${ }^{[3,4]}$ Vascularized bone grafts from various locations including the fibula, scapula and iliac crest may be indicated to stimulate bone formation and promote healing. However, harvest requires a complex microsurgery procedure, with the additional risk of including graft necrosis due to vessel thrombosis..$^{[5,6]}$ Allografts may be a reasonable alternative, as small cancellous allografts can remodel completely. Larger grafts may be incorporated by limited intramembranous bone formation. ${ }^{[1]}$ However, allografts may increase the risk of infectious disease transmission.

Recent progress in the fields of biotechnology and tissue engineering has offered new options for the repair of traumatic and nontraumatic bone defects. Mesenchymal stem cells (MSCs), which are multipotent adult stem cells of mesodermal origin, have been shown to play a critical role in tissue engineering. MSCs are an excellent potential source of cells for bone tissue engineering due to their excellent renewal ability and osteogenic differentiation capabilities. ${ }^{[7,8]}$ In addition to the bone marrow (BM), MSCs are also derived from the periosteum. It is well known that the development and regeneration of bone depend on the presence of periosteum and $\mathrm{BM} .{ }^{[9]}$ When transferred to the site of bone damage, MSCs multiply and differentiate into osteoblastic cells, contributing to the production of bone tissues that form a callus at the bone defect site. ${ }^{[10]}$ Alternatively, bone tissue engineering can be achieved via intramembranous ossification. ${ }^{[11]}$

The use of MSCs with an appropriate scaffold has been demonstrated to be promising in guiding bone tissue neoformation after implantation in the host. Cell repopulation can be achieved either by direct cell loading or indirect cell induction with osteogenic factors. ${ }^{[12,13]}$ Combining MSCs with appropriate scaffolds has been shown to improve the overall osteoconductivity of the scaffold. The search for an ideal scaffold has led to the development of reconstructive options to engineer new bone $(\mathrm{NB})$ tissue. The ideal scaffold should be biocompatible, noninfectious, resorbable, osteoconductive and osteoinductive. ${ }^{[14]}$ Demineralized bone matrix (DBM), which is derived from either allogenic or xenogenic bone, is available commercially for clinical application and satisfies some of these requirements. ${ }^{[4]}$ DBM has been used for several decades in humans for the treatment of nonunion and bone defects following injury or tumor resection. The process of demineralization using hydrochloric acid destroys potential bone forming agents, but also decreases antigenic stimulation and may expose the bone morphogenic protein located within the bone matrix..$^{[1,4]}$ This study is designed to evaluate the bone formation properties of a demineralized cancellous bone scaffold seeded with allogenic MSCs, with or without periosteum, in a critical sized bone defect model in rabbits.

\section{METHODS}

\section{Bone marrow mesenchymal stem cells isolation} and expansion

Bone marrow mesenchymal stem cells (BM-MSCs) were isolated from rabbits and cultured as reported previously. ${ }^{\mid 9,11,13,15]}$ The BM aspirates $(5 \mathrm{~mL})$ were obtained from the femurs of 5 rabbits that were 8 weeks old. The BM aspirates were layered over a Ficoll gradient and centrifuged at 2,000 rpm for $20 \mathrm{~min}$ at room temperature. Mononuclear cells at the interface were collected and cultured in Dulbecco's Modified Eagle Medium-Low glucose supplemented with $15 \%$ fetal bovine serum (FBS), $10 \mathrm{mM}$ L-glutamine, $10 \mathrm{ng} / \mathrm{mL}$ epidermal growth factor, $10 \mathrm{ng} / \mathrm{mL} \beta$-fibroblast growth factor and $1 \%$ antibiotic antimycotic solution $(10,000 \mathrm{U} / \mathrm{mL}$ penicillin, $10 \mathrm{mg} / \mathrm{mL}$ streptomycin and $25 \mu \mathrm{g}$ amphotericin B) (Sigma-Aldrich, USA). Cultures were maintained in a $\mathrm{CO}_{2}$ incubator (Shel Lab, USA) at $37{ }^{\circ} \mathrm{C}$ and $5 \% \mathrm{CO}_{2}$. The medium was replaced after 3 days and cell layers were washed twice with phosphate-buffered saline to remove nonadherent cells. The passage was carried out when cultures reached $90 \%$ confluence using $0.25 \%$ trypsin-ethylenediaminetetraacetic acid (Sigma-Aldrich, USA). Cell confluence was normally achieved after 12-14 days. ${ }^{[14,16-18]}$

\section{Scaffold materials}

Human demineralized cancellous bone (HDCB), which is a type of DBM and has been proven to be usable as scaffold material, was used in this experiment. HDCB was supplied from the Bone Bank at the National Institute of Burns. Fresh bones were aseptically harvested within the first $12 \mathrm{~h}$ after being shown to be free of any infectious disease. Bones were treated with $\mathrm{H}_{2} \mathrm{O}_{2}$, a mixture of methanol/chloroform, hydrochloric acid and phosphate buffer $\mathrm{pH}$ 7.4. Subsequently, the bones were dehydrated for $24 \mathrm{~h}$ until the water content remaining in the bones was less than $5 \%$. The bones were cut into blocks with dimensions of $1.5 \mathrm{~cm} \times 0.3 \mathrm{~cm} \times 0.5 \mathrm{~cm}$. A medullary hole was made in the bone blocks with a diameter of $1.5 \mathrm{~mm}$. The block was packaged and sterilized by gamma irradiation at a dose of $25 \mathrm{kGy}$. The sterilized bones were then preserved at $4{ }^{\circ} \mathrm{C}$.

Tissue engineered bone graft preparation in vitro Culture-expanded BM-MSCs were seeded evenly onto the HDCB scaffold. DHCB/BM-MSCs were cultured in T flasks (Thermo Scientific Nunc A/S, Denmark) filled with $5 \mathrm{~mL}$ DMEM containing $10 \%$ FBS and antibiotics. The grafts were placed in a vacuum desiccator and treated at a pressure of 100 torr for $100 \mathrm{~s}$, after which they were incubated at $37{ }^{\circ} \mathrm{C}, 5 \% \mathrm{CO}_{2}$ for 2 weeks. The medium was replaced every 3 days. ${ }^{[2,19-21]}$

\section{Animals and surgical procedure}

Twenty-eight male 8-week-old white New Zealand rabbits with a body weight of approximately $1.5 \mathrm{~kg}$ from the Experimental Laboratory of the Medical Training and Research Center, Hue Central Hospital, were used for the study. All the experimental study involving animals was approved by the Institutional Animal Care and Use 
Committee and the Ethics Committee of the Medical Training and Research Center. The rabbit bone defect model was established as described previously. ${ }^{[11,13]}$ The rabbit was anesthetized with a combination of intravenous sodium pentobarbital at $20 \mathrm{mg} / \mathrm{kg}$ and intramuscular ketamine at $50 \mathrm{mg} / \mathrm{kg}$. The anterolateral side of the forelimb was shaved and sterilized with $10 \%$ povidone-iodine. The radius was exposed through a longitudinal incision by gentle retraction of the muscles. An osteotomy gap of $1.5 \mathrm{~cm}$ was created in the diaphysis. Periosteum from the excised bone was preserved in the group that would later receive periosteal encapsulation of scaffolds. The ulna was left intact for mechanical stability [Figure 1]. The bone defect was created on both forelimbs of the animals. A total of 56 bone defects within the 28 rabbits were randomly assigned to one of the four groups for scaffold implantation: Group 1: HDCB graft only; Group 2: periosteum-wrapped HDCB graft; Group 3: HDCB graft seeded with BM-MSCs; and Group 4: periosteum-wrapped HDCB graft seeded with BM-MSCs. After implantation, muscle, fascia and skin were separately closed over the defect and no internal or external fixation was used. Forelimbs were postoperatively supported by a carton splint for one week. Each rabbit was administered 400,000 units of penicillin preoperatively on the 1 st postoperative day to prevent infection. All rabbits from each group were sacrificed 12 weeks after surgery for gross observation of the growth of callus, radiological assessment, histological analyses and biomechanical measurements.

\section{Gross observation}

Following sacrifice, both reconstructed radiuses were harvested and completely cleared from the soft tissues. The status of callus growth, degradation, bone healing and NB formation at the bone graft in the radius were observed.

\section{Radiological assessment}

Radius bone specimens in each group were X-rayed for the evaluation of bone formation and remodeling (Titan 2,000, COMED Medical Systems CO. Ltd., Korea). Assessment of NB formation and remodeling was based on the modified Lane and Sandhu radiological scoring system. ${ }^{[1]}$ Three experts blindly assessed the radiological scores, which were the sum of the scores of bone formation and remodeling. The score for NB formation was assigned as 0 (no NB formation), 1 (less than $25 \%$ NB formation),

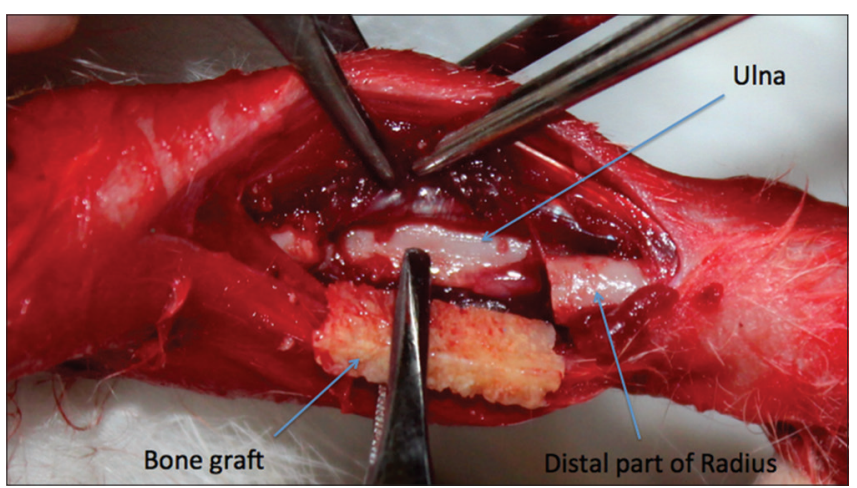

Figure 1: The procedure for the transplantation of cancellous bone graft into the segmental radial defect
2 (25-50\% NB formation), 3 (50-75\% NB formation) or 4 (more than $75 \%$ NB formation). The score assigned to the assessment of union was 0 (nonunion), 1 (possible union) or 2 (radiographic union). The proximal and distal unions of the bone graft were separately evaluated. The remodeling score assigned was 0 (no evidence of remodeling) 2 (intramedullary remodeling) or 4 (cortical remodeling). The maximum number of points, which could be achieved, was 10 for each reconstructed bone.

\section{Histological analyses}

Fifty-two specimens from the bone graft sites of the radius were successfully fixed with $10 \%$ paraformaldehyde, decalcified with sodium formate and embedded in paraffin. Four specimens in Group 1 experienced technical failures. Three sagittal sections were cut with a slow speed saw from each site at the distal, proximal and middle lines of the bone graft. Sections were then prepared and stained with hematoxylin and eosin. The micrographic images from the light microscope were quantified. Images from each section were taken to evaluate the bone formation ratio by a qualified pathologist blinded to the study. The NB formation ratio was calculated by the percentage area of bone tissue within the defect site, and a mean value was determined for each section.

\section{Biomechanical analysis}

The specimens of the radius of each group were loaded onto a multifunctional mechanical tester (Instron 5582 Universal Tester, USA) for the performance of a uniaxial compression test. The specimen was placed between compression plates. Force was applied to the specimens at a constant speed of $1 \mathrm{~mm} / \mathrm{min}$ until fracture occurred. Compressive stress and strain were calculated and plotted. Stress value at the point of yield (load-to-failure) was determined.

\section{Statistical analysis}

The data were presented as mean and standard deviation. The Student's $t$-test was performed to compare the difference between the mean values of two groups using Statistical Product and Service Solutions version 15.0 (SPSS, Inc., USA). Differences at a level of $P<0.05$ were considered to be statistically significant.

\section{RESULTS}

The wounds healed completely after one week and the rabbits were noted to regain full movement within two weeks. All the rabbits survived with normal behavior. No complications such as infection or necrosis were recorded prior to sacrifice.

\section{Gross observation}

At 12 weeks after surgery, radii implanted in Group 1 showed a small amount of callus and fibrous-like tissue in the interspaces between the defects and grafts. Partial degradation of the HDCB grafts was found. There was a significant amount of callus and bony union filled more than half of the defects in Groups 2 and 3. The HDCB grafts in these groups were almost degraded. In Group 4, good bony union was observed. Bone defects were almost completely remodeled with NB tissue and 
the HDCB grafts were completely degraded in this group [Figure 2].

\section{Radiological outcomes}

At 3 months postoperatively, there was a small amount of callus formation at the defect gaps in Group 1. NB formation was found to account for over half of the material at the reconstructed bone in Groups 2 and 3. Bone regeneration in the radius in Group 4 was observed to be the best, where callus formation was greatest in comparison to the other groups [Figure 3]. With the radiological score results, the mean score in Group 4 was $8.58 \pm 0.64$, which was significantly higher than the other three groups $(P<0.05)$. There was a significant difference between Groups 2 and $3(P<0.05)$. The mean scores in Groups 2 and 3 were significantly higher than those in Group $1(P<0.05)$ [Table 1$]$.

\section{Histological observations}

Inflammation was not observed in the grafted bone segment. Poor NB formation and capillary network were found at the interface between the graft and radius in Group 1. Both ends of the original radius were united with newly regenerated bone in Groups 2 and 3, while the HDCB scaffold was mostly degraded and cortical bone was only observed at the center of the defects. A larger amount of NB was generated along the entire scaffold structure and more capillaries were formed in the area of NB in Group 4. Group 4 showed superior bone union, cancellous bone, cortical bone, marrow formation and capillary formation in comparison to the other groups. Cortical bone was also found along the entire gap of the bone defect, bridging adjacent native bone [Figure 4]. The newly formed bone area in Group 4 increased to $80.5 \% \pm 4.96 \%$, which was significantly higher when compared with Group $3(64.12 \% \pm 11.31 \%)$, Group $2(49.79 \% \pm 11.69 \%)$ and Group $1(29.6 \% \pm 8.33 \%)(P<0.05)$ [Table 1]. Statistically

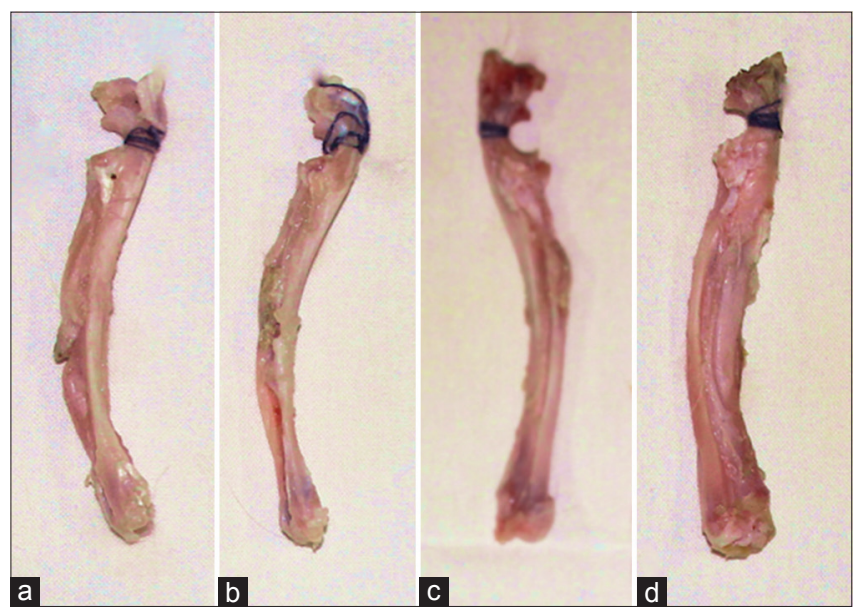

Figure 2: Gross observations of the reconstruction of radius at 3 months after surgery. (a) Small amount of callus and fibrous-like tissue in the interspaces between defect and human demineralized cancellous bone graft in Group 1; (b) callus formed in the defect repair by periosteum-wrapped human demineralized cancellous bone graft in Group 2; (c) significant amount of callus and bony union filled in the defect repair with the human demineralized cancellous bone graft seeded with mesenchymal stem cells in Group 3; (d) complete bone healing in the defect repair by periosteum-wrapped human demineralized cancellous bone graft seeded with bone marrow mesenchymal stem cells in Group 4 significant differences were found between Groups 2 and 3 $(P<0.05)$, while both groups were statistically superior as compared to Group $1(P<0.05)$ [Table 1].

\section{Biomechanical testing results}

Radii of rabbits with partial or complete union were subjected to biomechanical testing. Results of the biomechanical tests are summarized in Table 1. Group 4 showed the highest compressive strength $(P<0.05)$. Group 3 of HDCB grafts seeded with BM-MSCs showed significantly higher compressive strength than both Groups 1 and $2(P<0.05)$. The difference between Groups 1 and 2 was statistically significant $(P<0.05)$ [Table 1].

\section{DISCUSSION}

This study demonstrates the presence of NB formation and bone healing, as shown both radiologically and histologically, on demineralized cancellous bone graft seeded with BM-MSCs. Results were improved when BM-MSCs were associated with periosteum.

MSCs, periosteal cells and osteoblasts have all been successfully used for bone tissue engineering. ${ }^{[4,18]}$ In particular, BM-MSCs play a major role in the repair of bone defects. ${ }^{[22-25]}$ They are capable of self-replication and differentiation into osteocytes in appropriate culture conditions and can contribute to the regeneration of mesenchymal tissues such as bone. ${ }^{[3,26]}$ BM-MSCs can be rapidly expanded ex vivo without loss of their multi-lineage differentiation potential. ${ }^{[13]}$ They are readily available and amenable to genetic manipulation. BM-MSCs can, therefore, be viewed as a viable alternative for bone tissue engineering. ${ }^{[8,11,27,28]}$

The anatomy of the periosteum, its nutrient transport and its osteoinductive and osteoconductive capacities have been well described. ${ }^{[29]}$ Periosteum plays a primary role in bridging callus formation and participating in endochondral and intramembranous ossifications in fracture healing. ${ }^{[30]}$ Previous studies have shown that the
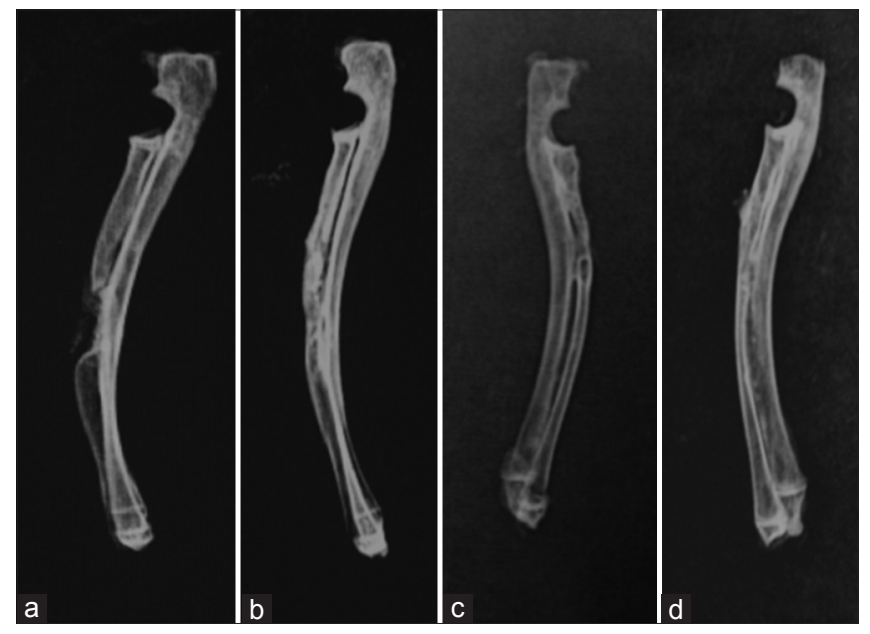

Figure 3: Results of X-ray at the 3 months postoperation. (a) A few calluses at the defect gap in Group 1; (b) significant new bone information at the reconstructed bone in Group 2; (c) more new bone formation between graft and bone tissue in Group 3; (d) almost remodeling of new formed bone along the entire gap of the bone defect in Group 4, and the cortical bone bridged to the adjacent native bone 
Table 1: Modified Lane and Sandhu radiological scores, mean new bone formation in Histology (\%), and mean compressive strength (MPa) of the rabbit's radius in each group at 3 months after surgery

\begin{tabular}{llccc}
\hline Group & Scaffold implantation & $\begin{array}{c}\text { Mean radiological } \\
\text { scores }\end{array}$ & $\begin{array}{c}\text { Mean compressive } \\
\text { strength (MPa) }\end{array}$ & $\begin{array}{r}\text { Mean new bone } \\
\text { in Histology (\%) }\end{array}$ \\
\hline 1 & HDCB only & $2.95 \pm 0.58$ & $31.14 \pm 6.72$ & $29.60 \pm 8.33$ \\
2 & Periosteum-wrapped HDCB & $5.57 \pm 0.51$ & $73.00 \pm 7.20$ & $49.79 \pm 11.69$ \\
3 & HDCB/BM-MSCs & $6.41 \pm 1.03$ & $80.57 \pm 8.50$ & $64.12 \pm 11.31$ \\
4 & Periosteum-wrapped HDCB/ & $8.58 \pm 0.64$ & $129.31 \pm 5.99$ & $80.50 \pm 4.96$ \\
& BM-MSCs & & &
\end{tabular}

HDCB: Human demineralized cancellous bone, BM-MSCs: Bone marrow mesenchymal stem cells

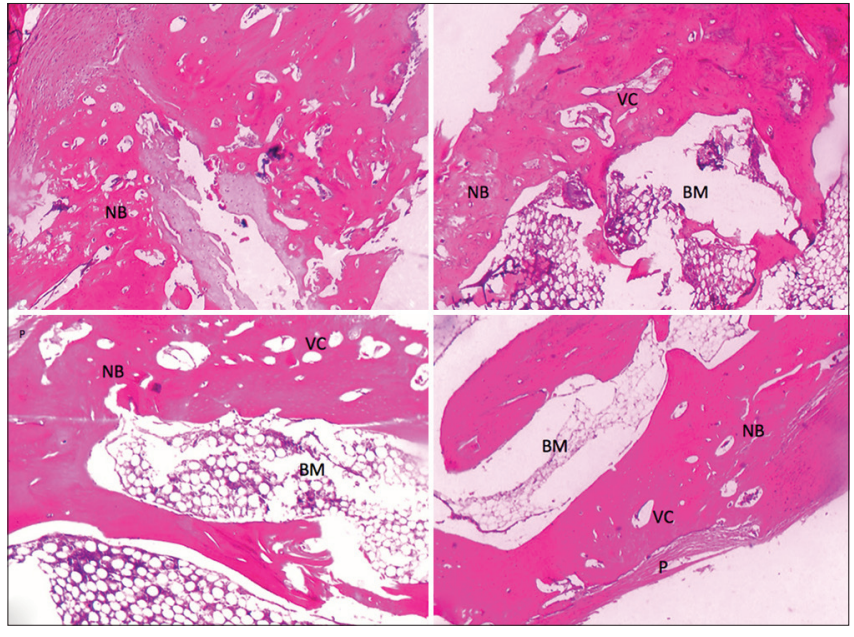

Figure 4: HE stained histological sections from the grafted bone of four groups at 3 months after implantation (original magnification, $\times 40$ ). NB: New bone, VC: Vascular cavity, BM: Bone marrow, P: Periosteal membrane

inner cambium layer is highly cellular and populated with cells, which influence bone formation and bone repair, including adult mesenchymal skeletal progenitor cells. ${ }^{[29,31]}$ These progenitor cells proliferate and differentiate into osteoblastic and chondroblastic cells, driving the process of bone repair via either direct intramembranous bone formation or indirect endochondral mechanisms, respectively. ${ }^{[32]}$ On the contrary, the absence of periosteum reduced by $75 \%$, the number of osteoblasts on devitalized bone graft, which correlated with the poor remodeling activity of the bone graft. ${ }^{[3]}$ These features indicate that periosteum should be considered to be a structure with regenerative capacity. This suggests the need to restore the essential osteogenic activity of periosteum on bone graft in combination with grafting of MB-MSCs. This approach assists in the early induction of a reparative response by an increase in the formation of a cortical shell around the grafted bone. ${ }^{[34,35]}$ Agata et al. ${ }^{[34]}$ have also shown that periosteal cells act as progenitor cells with the ability to proliferate and expand. Thus, periosteum-derived cells are another suitable source for bone tissue engineering.

Based on clinical observation, radiologic examination, histological analyses and biomechanical measurements, the current study supports the essential role of periosteum in the process of bone repair. In addition, the regenerative effect of combining BM-MSCs with periosteum showed better outcomes in both the quantity and quality as compared to BM-MSCs alone. Furthermore, the MB-MSCs used in the current study are derived from an allogenic source, which is more convenient for isolation and expansion when compared with periosteum-derived cells. To further enhance the current bone tissue engineering strategies, a successful cellular replacement for periosteum or tissue-engineered periosteum should be investigated. Zhang et al. ${ }^{[1]}$ previously reported successful regeneration of segmental bone defects in rabbit ulnas using periosteum encapsulated scaffolds seeded with MSCs, with an increase in the newly formed bone area to $80.1 \% \pm 9.6 \%$. This result is compatible with the results of the current study at $80.5 \% \pm 4.96 \%$.

Xenogeneic demineralized cancellous bone grafts, which have the advantages of favorable cellular compatibility and histocompatibility as a scaffold, have widely been used for the repair of short bony defects showing the induction of NB formation and good mechanical properties. Osteoinductive structures in demineralized bone graft include a series of low-molecular-weight glycoproteins with bone morphogenetic proteins. These proteins promote chondroblastic differentiation of mesenchymal cells and create NB formation via endochondral osteogenesis. ${ }^{[1,31,35]}$ The bone formation process increases when decalcification of cortical bone exposes osteoinductive growth factors buried within the mineralized matrix. However, bone grafting has not been successful in the repair of large bone defects. ${ }^{[13]}$ BM-MSCs, which can be seeded to the HDCB graft for construction of the tissue engineered bone graft, has been suggested as an effective option for the reconstruction of large bone defects.

In the group repaired by periosteum-wrapped HDCB graft seeded with BM-MSCs, bone healing and union were significantly accelerated as compared to the other three groups. Increased density at the graft site and early fusion of cortical bone were observed. In addition to NB formation demonstrated histologically, a significant amount of regenerated capillary vasculature between the NBs was also being observed in a high proportion of grafted bone pores. Zhang et al. ${ }^{[11]}$ reported similar results when incorporating MSCs and periosteum-loaded poly scaffolds. However, our findings have notable differences from the results of Zhang et al., ${ }^{[11]}$ as HDCB/BM-MSCs grafts were significantly superior to periosteum-wrapped HDCB grafts in terms of union rates and capillary density.

For improved biochemical analysis for bone regeneration, a three-point bending test should be performed to evaluate the degree of scaffold integration with the host bone. 
In conclusion, this study demonstrates that repair of bone defect in a rabbit model can be achieved through bone grafting using BM-MSCs implanted on a xenogeneic demineralized cancellous bone scaffold. NB formation was optimized with the preservation of the periosteum at the site of injury. The combination of biocompatible material, the ability for self-renewal and differentiation of MSCs with the augmenting effects of periosteum may prove to be an extremely promising approach in the fields of orthopedic and plastic surgery.

\section{Acknowledgment}

I acknowledge my colleagues at the Department of Hematology, Hue Central Hospital. I would also like to specially thank Dr. Bui Duc Phu, Dr. Nguyen Duy Thang, Dr. Phan Thi Thuy Hoa, Dr. Phan Hoang Duy, Dr. Dang Cong Thuan and Dr. Fréderic Schuind, for their excellent help and support.

\section{Financial support and sponsorship Nil.}

\section{Conflicts of interest}

There are no conflicts of interest.

\section{REFERENCES}

I. Bigham-Sadegh A, Shadkhast M, Khalegi MR. Demineralized calf foetal growth plate effects on experimental bone healing in rabbit model. Vet Arh 20I3;83:525-36.

2. Ng MH, Duski S, Idrus RB Tan KK, Yusof MR, Low KC, Rose IM, Mohamed Z, Bin Saim A. Repair of segmental load-bearing bone defect by autologous mesenchymal stem cells and plasma-derived fibrin impregnated ceramic block results in early recovery of limb function. Biomed Res Int 2014;20 I 4:3459I0.

3. Fialkov JA, Holy CE, Shoichet MS, Davies JE. In vivo bone engineering in a rabbit femur. J Craniofac Surg 2003;14:324-32.

4. Kneser U, Schaefer DJ, Polykandriotis E, Horch RE. Tissue engineering of bone: the reconstructive surgeon's point of view. J Cell Mol Med 2006; 10:7-19.

5. Cao L, Liu X, Liu S, Jiang Y, Zhang X, Zhang C, Zeng B. Experimental repair of segmental bone defects in rabbits by angiopoietin-I gene transfected MSCs seeded on porous $\beta$-TCP scaffolds. J Biomed Mater Res B Appl Biomater 2012;100:1229-36.

6. Lê Thua TH, Pham DN, Boeckx W, De Mey A. Vascularized fibular transfer in longstanding and infected large bone defects. Acta Orthop Belg 20। 4;80:50-5.

7. Kanczler JM, Oreffo RO. Osteogenesis and angiogenesis: the potential for engineering bone. Eur Cell Mater 2008; 15:100-14.

8. Patel DM, Shah J, Srivastava AS. Therapeutic potential of mesenchymal stem cells in regenerative medicine. Stem Cells Int 2013;2013:4962I8.

9. Ai J, Ebrahimi S, Khoshzaban A, Jafarzadeh Kashi TS, Mehrabani D. Tissue engineering using human mineralized bone xenograft and bone marrow mesenchymal stem cells allograft in healing of tibial fracture of experimental rabbit model. Iran Red Crescent Med J 20I2;14:96-I03.

10. Zomorodian E, Baghaban Eslaminejad M. Mesenchymal stem cells as a potent cell source for bone regeneration. Stem Cells Int 20I2;2012:980353.

II. Zhang X, Qi YY, Zhao TF, Li D, Dai XS, Niu L, He RX. Reconstruction of segmental bone defects in the rabbit ulna using periosteum encapsulated mesenchymal stem cells-loaded poly (lactic-co-glycolic acid) scaffolds. Chin Med J (Engl) 20।2; 125:403|-6.

12. Nooeaid P, Salih V, Beier JP, Boccaccini AR. Osteochondral tissue engineering: scaffolds, stem cells and applications. J Cell Mol Med 2012;16:2247-70.

13. Zhao M, Zhou J, Fang T, Dai W, Yin W, Dong J. Repair of bone defect with vascularized tissue engineered bone graft seeded with mesenchymal stem cells in rabbits. Microsurgery 201 I;31:130-7.

14. Wildemann B, Kadow-Romacker A, Pruss A, Haas NP, Schmidmaier G.
Quantification of growth factors in allogenic bone grafts extracted with three different methods. Cell Tissue Bank 2007;8:107-14.

15. Chen L, Zhu WM, Fei ZQ, Chen JL, Xiong JY, Zhang JF, Duan L, Huang J, Liu Z, Wang D, Zeng Y. The study on biocompatibility of porous nHA/PLGA composite scaffolds for tissue engineering with rabbit chondrocytes in vitro. Biomed Res Int 2013;2013:412745.

16. Kon E, Filardo G, Roffi A, Di Martino A, Hamdan M, De Pasqual L, Merli ML, Marcacci M. Bone regeneration with mesenchymal stem cells. Clin Cases Miner Bone Metab 20I2;9:24-7.

17. Pang L, Hao W, Jiang M, Huang J, Yan Y, Hu Y. Bony defect repair in rabbit using hybrid rapid prototyping polylactic-co-glycolic acid/ beta-tricalciumphosphate collagen I/apatite scaffold and bone marrow mesenchymal stem cells. Indian J Orthop 2013;47:388-94.

18. Wang X, Wang Y, Gou W, Lu Q, Peng J, Lu S. Role of mesenchymal stem cells in bone regeneration and fracture repair: a review. Int Orthop 2013;37:2491-8.

19. Annibali S, Cicconetti A, Cristalli MP, Giordano G, Trisi P, Pilloni A, Ottolenghi L. A comparative morphometric analysis of biodegradable scaffolds as carriers for dental pulp and periosteal stem cells in a model of bone regeneration. J Craniofac Surg 20I3;24:866-7I.

20. Chatterjea A, Renard AJ, Jolink C, van Blitterswijk CA, De Boer J. Streamlining the generation of an osteogenic graft by $3 \mathrm{D}$ culture of unprocessed bone marrow on ceramic scaffolds. J Tissue Eng Regen Med 2012;6:103-12.

21. Johnson EO, Troupis T, Soucacos PN. Tissue-engineered vascularized bone grafts: basic science and clinical relevance to trauma and reconstructive microsurgery. Microsurgery 201 I;31:176-82.

22. Zhang W, Zhang F, Shi H, Tan R, Han S, Ye G, Pan S, Sun F, Liu X. Comparisons of rabbit bone marrow mesenchymal stem cell isolation and culture methods in vitro. PLoS One 2014;9:e88794.

23. Hosseinkhani M, Mehrabani D, Karimfar MH, Bakhtiyari S, Manafi A, Shirazi R. Tissue engineered scaffolds in regenerative medicine. World J Plast Surg 20I4;3:3-7.

24. Li M, Ikehara S. Bone-marrow-derived mesenchymal stem cells for organ repair. Stem Cells Int 2013;2013:132642.

25. Ohgushi $\mathrm{H}$. Osteogenically differentiated mesenchymal stem cells and ceramics for bone tissue engineering. Expert Opin Biol Ther 20। 4; 14:197-208.

26. Wang B, Sun C, Shao Z, Yang S, Che B, Wu Q, Liu J. Designer self-assembling Peptide nanofiber scaffolds containing link protein $\mathrm{N}$-terminal peptide induce chondrogenesis of rabbit bone marrow stem cells. Biomed Res Int 20|4;2014:421954.

27. Nakamura O, Kaji Y, Imaizumi Y, Yamagami Y, Yamamoto T. Prefabrication of vascularized bone allograft in a recipient rat using a flow-through vascular pedicle, bone morphogenetic protein, and bisphosphonate. J Reconstr Microsurg 2013;29:24I-8.

28. Rust PA, Kalsi P, Briggs TW, Cannon SR, Blunn GW. Will mesenchymal stem cells differentiate into osteoblasts on allograft? Clin Orthop Relat Res 2007;457:220-6.

29. Colnot C, Zhang X, Knothe Tate ML. Current insights on the regenerative potential of the periosteum: molecular, cellular, and endogenous engineering approaches. J Orthop Res 2012;30:1869-78.

30. Lin Z, Fateh A, Salem DM, Intini G. Periosteum: biology and applications in craniofacial bone regeneration. J Dent Res 2014;93:109-16.

3I. Ferretti C, Mattioli-Belmonte M. Periosteum derived stem cells for regenerative medicine proposals: boosting current knowledge. World J Stem Cells 2014;6:266-77.

32. Evans SF, Chang H, Knothe Tate ML. Elucidating multiscale periosteal mechanobiology: a key to unlocking the smart properties and regenerative capacity of the periosteum? Tissue Eng Part B Rev 2013;19:147-59.

33. Zhang X, Awad HA, O'Keefe RJ, Guldberg RE, Schwarz EM. A perspective: engineering periosteum for structural bone graft healing. Clin Orthop Relat Res 2008;466: 1777-87.

34. Agata H, Asahina I, Yamazaki Y, Uchida M, Shinohara Y, Honda MJ, Kagami H, Ueda M. Effective bone engineering with periosteum-derived cells. J Dent Res 2007;86:79-83.

35. Chang $\mathrm{H}$, Knothe Tate ML. Concise review: the periosteum: tapping into a reservoir of clinically useful progenitor cells. Stem Cells Transl Med 20। $2 ; 1: 480-9 \mid$. 